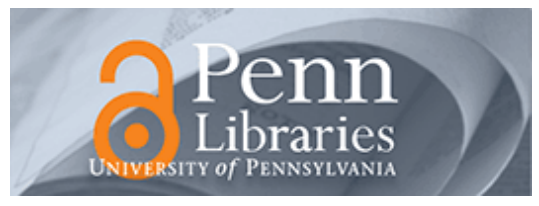

University of Pennsylvania

ScholarlyCommons

Finance Papers

Wharton Faculty Research

$5-2012$

\title{
Unpacking Team Familiarity: The Effects of Geographic Location and Hierarchical Role
}

Bradley Staats

University of Pennsylvania

Follow this and additional works at: https://repository.upenn.edu/fnce_papers

Part of the Finance and Financial Management Commons, and the Social and Behavioral Sciences Commons

\section{Recommended Citation}

Staats, B. (2012). Unpacking Team Familiarity: The Effects of Geographic Location and Hierarchical Role. Production and Operations Management, 21 (3), 619-635. http://dx.doi.org/10.1111/

j.1937-5956.2011.01254.x

This paper is posted at ScholarlyCommons. https://repository.upenn.edu/fnce_papers/64

For more information, please contact repository@pobox.upenn.edu. 


\title{
Unpacking Team Familiarity: The Effects of Geographic Location and Hierarchical Role
}

\author{
Abstract \\ Examination of team productivity finds that team familiarity, i.e., individuals' prior shared work experience, \\ can positively impact the efficiency and quality of team output. Despite the attention given to team \\ familiarity and its contingencies, prior work has focused on whether team members have worked \\ together, not on which team members have worked together, and under what conditions. In this paper, I \\ parse overall team familiarity to consider effects of geographic location and the hierarchical roles of team \\ members. Using data on all software-development projects completed over 3 years at a large Indian firm \\ in the global outsourced software services industry, I find that team familiarity gained when team \\ members work together in the same location has a significantly more positive effect on team \\ performance compared with team familiarity gained while members were collaborating in different \\ locations. Additionally, I find that hierarchical team familiarity (a manager's experience with front-line \\ team members) and horizontal team familiarity (front-line team members' experience gained with one \\ another) have differential effects on project team performance. These findings provide insight into the \\ relationship between team experience and team performance.

\section{Disciplines} \\ Finance and Financial Management | Social and Behavioral Sciences
}




\title{
Unpacking Team Familiarity: The Effects of Geographic Location and Hierarchical Role
}

\author{
Bradley R. Staats \\ University of North Carolina at Chapel Hill \\ Chapel Hill, NC 27599-3490 \\ Tel: 919.962 .7343 \\ bstaats@unc.edu
}

February 23, 2011

\section{Acknowledgments}

I would like to thank Sambuddha Deb, Venkatesh Hulikal, Sowmya Narayanan, Alexis Samuel, and many other individuals at Wipro for their significant commitments of time and effort, making this project possible. Sincere thanks also go to Rob Huckman, Andy King, Gary Pisano, and David Upton for extensive advice, discussions, and encouragement. Ethan Bernstein, Francesca Gino, Dave Hofmann, Melissa Valentine, Department Editor Michael Lapré, the senior editor, and reviewers of this paper's earlier drafts offered particularly valuable comments and suggestions. This work never could have been done without the generous support provided by National Science Foundation Grant \#0943210. All errors are my own. 


\title{
Unpacking Team Familiarity: The Effects of Geographic Location and Hierarchical Role
}

\begin{abstract}
Examination of team productivity finds that team familiarity, i.e., individuals' prior shared work experience, can positively impact the efficiency and quality of team output. Despite the attention given to team familiarity and its contingencies, prior work has focused on whether team members have worked together, not on which team members have worked together, and under what conditions. In this paper, I parse overall team familiarity to consider effects of geographic location and the hierarchical roles of team members. Using data on all software development projects completed over three years at a large Indian firm in the global outsourced software services industry, I find that team familiarity gained when team members work together in the same location has a significantly more positive effect on team performance compared to team familiarity gained while members were collaborating in different locations. Additionally, I find that hierarchical team familiarity (a manager's experience with front-line team members) and horizontal team familiarity (front-line team members' experience gained with one another) have differential effects on project team performance. These findings provide insight into the relationship between team experience and team performance.
\end{abstract}

Key Words: Distributed teams, Knowledge work, Software, Team familiarity, Team productivity

\section{Introduction}

In a variety of settings ranging from scientific exploration and software development to consulting and service delivery, organizations are turning to teams of knowledge workers to execute projects that are vital to the organizations' success (Edmondson and Nembhard 2009). Substantial attention has been directed to identifying factors that may improve these knowledge teams' productivity (Haas and Hansen 2007; O'Leary and Mortensen 2010). One such factor is team familiarity: team members' shared prior work experience. Earlier researchers' work has found that team familiarity not only has a positive effect on project team performance (Reagans, Argote and Brooks 2005; Espinosa et al. 2007; Huckman, Staats and Upton 2009), but it also helps teams cope with contingencies such as coordination complexity (Espinosa et al. 2007) and diversity in their members' prior experience (Harrison et al. 2002; Huckman and Staats 2011).

Despite the attention that has been given to team familiarity and its contingencies, the underlying interactions remain relative mysteries. In this paper, I examine not just whether team members have worked together, but which members have worked together, an important distinction for theorizing about team familiarity. Individuals' characteristics and roles shape how they gather, interpret, and act on 
information (Katz and Kahn 1966). I focus here on two such characteristics: geographic location and the hierarchical roles of team members in the workplace. These characteristics increase in theoretical import when one assumes that teams are often geographically distributed and fluid in nature (i.e., members execute a project, then teams are split and members assigned to new projects, Arrow and McGrath 1995).

I first explore how benefits of team familiarity accrue differentially when team members are in different locations. Espinosa et al. (2007) found team familiarity to be more valuable for teams that are geographically dispersed. I investigate whether experience accumulated between individuals results in different productivity benefits if the experience was shared at the same work site or while the members were working at different sites. When individuals work in different locations, both communication and shared understanding may suffer (Allen 1977; Jarvenpaa and Leidner 1999; Cramton 2001). While prior shared work experience may help to overcome these problems, the difficulties could, alternatively, eliminate any potential benefits from team familiarity. I therefore separate the effects of same-location team familiarity (i.e., prior experience gained between two individuals in the same geographic location) from those of different-location team familiarity (i.e., prior experience gained between two individuals while they were in different geographic locations). I hypothesize that same-location team familiarity will affect performance more positively than will different-location team familiarity.

In addition to teasing out effects attributable to work location, I also explore the effect of hierarchical roles on the relationship between team familiarity and performance. Due to differences in factors such as decision rights (Jensen and Meckling 1976) and situated knowledge (Tyre and von Hippel 1997) within hierarchical roles, the impact of prior shared experience on team performance may differ based on individuals' hierarchical roles (i.e., manager vs. team member). However, prior research on team familiarity has not distinguished between individuals' roles on teams; rather, interactions across roles have been treated as equivalent. I therefore examine here the separate effects on team performance of hierarchical team familiarity (i.e., a manager's prior work experience with team members) and horizontal team familiarity (i.e., subordinate team members' prior work experience with one another).

The following section introduces relevant prior literature as well as this study's three hypotheses. 
Next, I discuss the data and empirical strategy in Section 3, before presenting the results and analysis in Section 4. Finally, in Section 5, I discuss the results and offer concluding remarks.

\section{Team Familiarity, Geographic Location, and Hierarchical Roles}

In this section, I first examine why workers' previous experience working with the same team members (i.e., team familiarity) may improve team performance compared to a group of individuals with the same amount of task experience as the aforementioned team, but working with complete strangers. I then investigate the differential benefits accrued from working together under conditions that clarify the impacts of geographic location and hierarchical role relationships.

\subsection{Team Familiarity and Performance}

Team members who repeatedly collaborate with one another may develop social capital and improve their ability to coordinate actions (Goodman and Leyden 1991). With recurring interactions, team members build rapport and so avoid the process losses that occur in newly formed groups(Steiner 1972). However, too much team familiarity may be detrimental to performance, as Katz (1982) found a negative secondorder effect. Since Katz's study required over five years for the negative effect to appear, teams in existence for only months, as opposed to years, may be less likely to suffer from this effect. More generally, team familiarity helps teams to locate and share knowledge.

Before teams can use new knowledge, they must first locate it. Individuals have mixed success recognizing valuable knowledge within a group (Littlepage, Robison and Reddington 1997). A Transactive Memory System (TMS) is one way a team can increase its members' likelihood of accomplishing this task (Wegner 1987). As team members work together, they enact a TMS that includes a representation of which person knows what (Lewis 2003). This enables the "encoding, storing, retrieving, and communicating [of] group knowledge" (Lewis, Lange and Gillis 2005: 581). Experience working together may help managers to allocate tasks effectively and team members to coordinate across specialized roles (Liang, Moreland and Argote 1995; Reagans et al. 2005). Thus, by knowing who knows what, team members can coordinate activities more successfully (Moreland, Argote and Krishnan 1998). 
Even if knowledge is located, it still must be shared by sender and recipient (Lapré, Mukherjee and Wassenhove 2000). Team members sharing knowledge may combine that knowledge in new ways or find higher-order abstractions, creating new knowledge. Szulanski (1996) finds that it is not a lack of motivation, but rather "knowledge-related factors" that are primary variables explaining why knowledge is not shared successfully inside organizations. Working with the same team members may increase the quantity and quality of knowledge sharing (Monteverde 1995). Members' recurring interactions help their team to establish communication channels and a common language (Weber and Camerer 2003; Narayanan, Balasubramanian and Swaminathan 2010).

As team members share experiences, they may build trust, yielding performance benefits (Uzzi 1997). Strong ties between team members may lead to more creative problem-solving (Sosa 2010). Team beliefs about such notions as positive social acceptance or psychological safety may be created to enable learning and improve performance (Gruenfeld et al. 1996; Edmondson 1999; Hinds et al. 2000; Siemsen et al. 2009). In psychologically safe environments, team members may be more likely to share mistakes and take risks, resulting in more experimentation and more innovative thinking (Edmondson 1996; Lee et al. 2004). Shared experiences may also increase team members' willingness to act on useful knowledge from others (Kane, Argote and Levine 2005). Thus, team familiarity may enable the creation of a learning system that aids in the ongoing application of new knowledge (Lewis et al. 2005).

\subsection{Geographic Location and Team Familiarity}

Given companies' needs to access distributed employee expertise to reach a globally dispersed customer base, and to draw upon low-cost human capital, geographically dispersed teams are a reality of the business environment in the twenty-first century (Gibson and Cohen 2003). Not surprisingly, then, a great deal of work has examined consequences of geographic dispersion, considering location, workday time, and cultural differences (Hinds and Kiesler 2002; O'Leary and Cummings 2007). Such work has found that distributed teams may encounter difficulties due to less communication about a task (Allen 1977), decreased face-to-face interaction (Kiesler and Cummings 2002), higher levels of electronic communication (Majchrzak, Malhotra and John 2005), increased conflict (Hinds and Mortensen 2005), 
and lower levels of trust (Jarvenpaa and Leidner 1999).

For this paper, the question is: why might familiarity gained between workers at different geographic locations be less beneficial for teams than familiarity gained between workers at the same location? Geographical separation may limit the benefits of working together for both locating and sharing knowledge within the team. For the former, when team members are separated geographically, they are less likely to collaborate and to engage in face-to-face or spontaneous communication (Festinger, Schachter and Back 1950; Allen 1977; Kiesler and Cummings 2002). Team members also lose the ability to informally observe other team members' actions (Armstrong and Cole 2002). The changes in team members' communication and interactions may mean that team members do not gain the same level of knowledge about distant members' expertise as they do about local members' expertise, thus compromising their ability to locate relevant knowledge within the team.

Team members' geographic separation might also impair the knowledge-sharing benefits of team familiarity. Geographic separation limits the volume and effectiveness of communication (van den Bulte and Moenaert 1998). In addition to challenges posed by geographic boundaries, time-zone differences may limit real-time communication and problem-solving (O'Leary and Cummings 2007). Lower-quality communication and a lack of mutual knowledge (Cramton 2001) may harm knowledge-sharing.

Workers located in different places may also affect dynamics within a team in a way that negates benefits of team familiarity. One worker may be unable to verify the accuracy of knowledge shared by her distant colleague (Sorenson and Audia 2000; Metiu 2006). Workers located in different parts of the world also might encounter increased conflict and problems with trust (Hinds and Bailey 2003; Hinds and Mortensen 2005). Even when trust forms, it may be fragile and unable to withstand the uncertain conditions that teams often encounter (Jarvenpaa and Leidner 1999).

Altogether, these effects may lessen the expected benefit of team familiarity when workers are at different locations, leading to this study's first hypothesis:

HYPOTHESIS 1. Same-location team familiarity has a larger positive effect on team operational performance than does different-location team familiarity. 


\subsection{Hierarchy and Team Familiarity}

Scholars have long studied the differing roles and activities of managers and workers (Taylor 1911; Marx and Engels 2002). Despite this recognized importance of studying different roles (Katz and Kahn 1966), prior work on team familiarity has not differentiated between the hierarchical roles that individuals have within a team; rather, research has treated interactions across roles as equivalent. The differences may prove to be particularly important, however, when effects of team familiarity on team performance are examined. For example, when individuals interact across hierarchical levels, their situated knowledge (i.e., knowledge from an individual's context, Tyre and von Hippel 1997) and decision rights (Jensen and Meckling 1976) are likely to impact their perceptions of conditions and thus their actions.

In many settings, teams include members at three hierarchical levels, such as a project manager, a middle manager, and a project engineer. The project manager leads the team and project engineers execute the work, while middle managers serve a coordination role, both interfacing with the project manager and assisting with work completion. To evaluate whether individuals' interactions within certain role relationships differentially shape team performance, I next examine hierarchical team familiarity (i.e., prior experience between project managers and project engineers) and horizontal team familiarity (i.e., prior experience between project engineers). ${ }^{1}$

\subsection{Hierarchical Team Familiarity: Project Managers and Project Engineers}

A team may benefit in many ways when a manager and team members have prior shared work experience. For example, through repeated interactions with engineers, a project manager is able to locate team members' relevant knowledge. Having observed the engineers previously, a project manager may know the complexity of work that an individual can handle as well as the engineer's likelihood of completing work on time. By successfully allocating work, a manager can improve team coordination and team performance (Malone and Crowston 1994; Cummings, Espinosa and Pickering 2009).

\footnotetext{
${ }^{1}$ Since I am interested in the impact of project manager-project engineer experience and project engineer-project engineer experience on performance, I do not hypothesize about the project manager-middle manager dyad. Since middle managers have an integrative role (managing and performing tasks), ex ante, in which group to place them is unclear. All reported results hold if I estimate coefficients for project manager-middle manager and middle manager-project engineer team familiarity.
} 
With repeated interactions, the project manager and engineers may build rapport, resulting in a higher comfort level and therefore more sharing of information (Hofmann, Morgeson and Gerras 2003). This information could be of limited value to a project manager, however, if she is unable to apply it to improve performance. For example, Brooks' Law, a well-known axiom in software engineering, states that adding manpower to a late project simply makes it later (Brooks 1975). To combat this problem, organizations have developed many tools and practices to help project managers effectively manage projects. For example, a project management system may enable managers to track schedule and effort performance relative to plan nearly continuously. By providing data and training project managers to incorporate this data into their decision-making, companies add rigor to a process that is often considered an art (Beck and Boehm 2003). This foundation allows project managers to benefit from prior shared work experience. If engineers bring an issue to a manager, the manager is able to make changes in response. Also, once a project manager learns of a problem from either an engineer or the system, she can use her prior knowledge of the engineers to assign new work effectively. Therefore, I hypothesize:

HYPOTHESIS 2. Hierarchical team familiarity increases project efficiency.

\subsection{Horizontal Team Familiarity: Project Engineers with One Another}

While horizontal team familiarity provides many of the benefits discussed above, there are two structural differences: (1) no one in this group has operational authority for the project and (2) engineers are closer to the frontline work (i.e., writing code). Although the lack of formal authority means these individuals do not have complete discretion to respond to obtained knowledge as they see fit, the second point may be particularly important for performance. Since engineers frequently work together on tasks, they may have a more realistic view of problems. Additionally, with repeated experience, engineers may be able to exert peer pressure to limit free-riding and improve productivity (Kandel and Lazear 1992).

Horizontal familiarity may also have benefits for the process of help-seeking. When faced with complex and uncertain work, individuals often need to consult with others to make sense of the work and derive a solution to the problem at hand (Allen 1977). While individuals often need help to solve 
problems, they might not turn to the most qualified person for help due to interpersonal risks involved in help-seeking (Lee 1997). Hofmann et al. (2009) find that when a provider of help is seen as accessible or trustworthy, a potential help-seeker is more likely to seek help from such an expert rather than from a less reliable but more approachable individual. Since experience working together may build rapport and increase trust within a team, it increases the likelihood that team members will seek and receive help from the most qualified person possible. This would help project teams build informal, advice-seeking networks and improve formal processes such as peer review and testing (Leonardi 2007; Narayanan, Balasubramanian and Swaminathan 2009). Thus:

\section{HYPOTHESIS 3. Horizontal team familiarity increases project quality.}

\section{Data and Empirical Strategy}

The company under study for this research, Wipro Technologies, is a global provider of software services, headquartered in India. Wipro offers a wide array of technology-enabled business solutions such as application development and R\&D services. As of December 31, 2006, the time of the data collection, Wipro had annualized revenues greater than three billion dollars and employed more than 66,000 people.

In the empirical analyses following, I examine software-development projects. Organizations often struggle with the complex and uncertain activities of development projects, unable to learn from their experience (Herroelen 2005; Boh, Slaughter and Espinosa 2007). As teams design solutions, write software code to meet specifications, and then test and implement the solutions, they have to manage the coordination of team activities as well as coordination with customer actions and systems (Faraj and Sproull 2000; Stewart 2003). Focusing on development projects provides both objective performance measures and controls for comparison across projects.

\subsection{Data}

The data analyzed begin with all 1,137 development projects completed at Wipro between January 2004 and December 2006. In addition to the project data, I have compiled complete human capital information on the 12,709 employees who worked on these projects. Typically, individuals work on one project at a 
time. I also have historical individual data detailing all individual project assignments since 2000 (not including project outcome information, however). I construct individual employee work histories to capture, over time, an individual's experience with other team members. To build the sample for analysis, I remove projects missing data ${ }^{2}$ and those projects with fewer than two project engineers ${ }^{3}$, yielding a final sample of 638 projects. The final sample, then, consists of all software development projects completed at Wipro over the three-year period that use kilolines of code as their unit of measurement. Comparing observable information for projects missing data to information for projects missing no data reveals no substantial differences in the variables of interest. In the sample, the median project included twelve team members $(\mu=18.4, \sigma=17.9)$ and lasted six months ( $\mu=232$ days, $\sigma=156$ days).

Wipro uses robust processes for data-recording and tracking. The company was first in the world to be certified at Level 5 for the Capability Maturity Model Integrated Version 1.1 (SEI 2001; Wipro 2008). The quality processes compliant to Level 5 status, including precise tracking of operational performance, are automated through an internally developed project-management tool. Project managers use the tool to submit regular reports, while all personnel use the tool to record their project assignments each week. Reports go through a quality-assurance process, and are subject to random audits by Software Engineering Process Group (SEPG) personnel. I have also extracted additional employee project assignment, role, and demographic information from the company's multiple human resource systems.

\subsubsection{Dependent Variables}

My dependent variables capture project efficiency (whether a project was delivered on budget, with respect to hours, and on time) and project quality.

Effort deviation. To measure a project's effort deviation, I create a continuous variable that measures the percentage by which a project exceeds or misses its estimate. To do this, I subtract a project's estimated effort from its actual effort and then divide by estimated effort. I divide by estimated effort in order to

${ }^{2}$ Of the projects removed, 468 are missing kilolines of code (KLOC). Not all projects use KLOC as their unit of measurement: not all projects include coding, so do not have KLOC and thus are excluded from the analysis. An additional twenty projects are missing one other variable of interest.

${ }^{3}$ To examine horizontal and hierarchical team familiarity, I must have at least one project manager and two project engineers on a team (i.e., three team members) in order for each measure to be meaningful. 
normalize for project size, since larger projects are likely to have larger absolute differences.

Schedule deviation. To measure how well a project performs with respect to its schedule, I construct a variable, schedule deviation, that subtracts a project's estimated due date from its actual due date and then normalize by the project's estimated duration. Examining the data reveals that more than $70 \%$ of projects are delivered on the precise day their project is due. Discussions with Wipro reveal that it is often not possible to deliver a project early, as customers require significant advance notice in order to schedule their own resources (e.g., one customer only permits rescheduling of delivery dates with more than thirty days' notice). Thus, given that schedule performance is left-censored, I analyze it using Tobit regression ${ }^{4}$.

Sales personnel at Wipro create the initial effort and schedule estimates. During a project, both estimates may be altered - typically due to a customer's change in project scope. To revise an estimate, the project manager must obtain the customer's agreement. Subsequently, Wipro business finance and quality managers also must approve the request. This process is designed to ensure that project managers do not alter project estimates simply because a project is not performing to expectations. For my analyses, I use the revised estimates since these most accurately encompass projects' ultimate goals.

Quality. In many but not all development projects, the final step is customer acceptance testing: Wipro gives the finished code to the customer for testing against the project's pre-specified metrics. The testing yields a count of defects, done by either the customer or the customer's designate so a project team cannot manipulate the test results. When zero defects are recorded, SEPG personnel confirm that testing was undertaken. Customer acceptance testing is a commonly used metric in software engineering (Boehm 1981), measuring a project's conformance quality. Thus, to evaluate a given project's quality performance, I use post-delivery defects: a count of the defects found in testing.

\subsubsection{Independent and Control Variables}

Overall team familiarity. I first calculate overall team familiarity. To do so, I count the number of prior

\footnotetext{
${ }^{4}$ An alternative empirical approach involves using a dichotomous outcome variable (whether a project is delivered on time, or not). Replacing schedule deviation with a dichotomous outcome variable, and then running conditional logistic regression models, does not alter my findings.
} 
projects on which each pair of individuals on a team has worked together over the past three years. I then sum these values across all unique pairings on the team and divide by the number of possible unique pairs $-N(N-1) / 2$ - where $N$ is team size. Consistent with prior literature, this measure for team familiarity captures "the average amount of experience that team members have working with each other" (Reagans et al. 2005, p. 873; see also Espinosa et al. 2007). By using this measure, I examine team members' prior shared work experience rather than determining whether individuals are in the same social club (Harrison et al. 2003) or knew each other before an experiment (Gruenfeld et al. 1996).

I use a three-year period to capture the fact that, as with learning (Argote, Beckman and Epple 1990), team familiarity may decay over time. Also, the three-year cutoff permits observation of several project cycles, as the average project lasts six months. Sensitivity analyses with two- and four-year windows generate the same pattern of results.

Location team familiarity. In order to test Hypothesis 1, I divide the team familiarity variable into two separate measures to capture whether prior interactions between team members occurred when the individuals were located at the same or different locations. This approach resembles that used in studies that take one cumulative experience variable and divide it into two cumulative experience variables representing different categories (e.g., firm-specific and non-firm-specific experience in Huckman and Pisano 2006). For same-location team familiarity, I count the number of prior projects on which each pair of individuals on a team worked together over the past three years in the same location. I then sum these values across all unique pairings on the team and divide by the number of possible unique pairs. For different-location team familiarity, I follow a similar process, but count only projects on which the individuals in a given pair were in different locations.

Hierarchical role team familiarity. To test Hypotheses 2 and 3, I calculate hierarchical team familiarity and horizontal team familiarity. This approach, again, takes the team familiarity variable and divides prior interactions across two categories. To calculate hierarchical team familiarity, I count the number of projects that a project manager executed with each project engineer on the team over the prior three years, 
then divide by the number of non-middle manager team members minus one. For projects with more than one manager, I average the value across project managers (and also count project managers' prior projects with each other). To compute horizontal team familiarity, I remove project and middle managers, then follow the same process as for overall team familiarity.

In addition to the variables discussed, I control for other factors that affect performance:

Task change. During a project, requirements may change due to shifting customer demand. This variable, task change, which is recorded within the Wipro project management system, captures the percentage of a project's requirements that are changed. Projects facing changing requirements may encounter difficulties as new work is integrated and communication patterns are readjusted to match the new workflow (Sosa, Eppinger and Rowles 2004; Gokpinar, Hopp and Iravani 2010; Huckman and Staats 2011).

Role experience. I wish to control for the baseline experience of the team. Prior work has shown that role experience (the time each individual has spent in her hierarchical role) is an appropriate measure of team experience (Huckman et al. 2009). I calculate role experience by identifying when a person first assumed the role she holds on a project, and use this value to determine the time (in years) that have passed prior to the project's start date. I construct the team value by weighting each individual's value according to the number of days she was on the project and averaging across team members. Fewer than $5 \%$ of project managers (PMs) are promoted before the historical data begins, so I impute role experience for these (PMs). Substituting a wide range of values to check robustness does not change the results.

Contract type. Development contracts at Wipro are either fixed price (FPP) or time and materials (T\&M). For a FPP, Wipro and the customer agree to the requirements and a set payment. In a T\&M contract, the customer pays a negotiated rate for hours worked on the project. To capture this distinction, I use an indicator variable, contract type, which equals one if a contract is FPP or zero for T\&M.

Team dispersion. Work is typically completed both "offshore" in Wipro's facilities in India, and onsite at a customer's location. Teams' performance may suffer from coordination difficulties arising from completing work in multiple locations (Cummings et al. 2009). Alternatively, dispersed teams may benefit from access to pools of knowledge resident in multiple locations (Cummings 2004). To control for 
such effects from dispersion, I calculate a variable, team dispersion, which equals the percentage of a team's hours that are completed at Wipro's offshore facilities if this value is less than $50 \%$. If it is greater than $50 \%$, then I subtract the value from one. Thus, I am left with a variable that is bounded between 0 and 0.5 . I calculate this variable using this approach since a team that completes $80 \%$ of its work offshore and $20 \%$ onsite is dispersed similarly to a team that completes $20 \%$ of its work offshore and $80 \%$ onsite ${ }^{5}$.

Complexity. To control for project complexity, I create a composite variable based on four underlying measures: kilolines of new source code written (KLOC), estimated total person-hours, total number of individuals who worked on the project, and estimated project duration, in days. I log each of these variables to control for scale effects and outliers. I next perform a principal components analysis with the variables, and each loads with a positive value on the first component $(0.47,0.55,0.52$, and 0.46 , respectively). The first component's Eigenvalue is 2.98 , which explains $74 \%$ of the variance. I use these values to create the complexity composite variable for each project. Using the four underlying variables instead of the composite variable does not materially change the reported results.

Start year. To control for changing internal and external conditions at the firm level, I include indicators for the year in which a project started.

Software languages. To control for differences in the software language used, I include indicator variables for the classes of language that appear in the data (C, C++, Java, query (e.g., SQL), markup (e.g., HTML), BASIC, and Other is the 'Excluded' category). Additionally, some development projects (33\% of the data) require more than one software language to meet their objectives. Since a project with multiple languages may be more difficult to complete than one the same size with only one language, I include an indicator set to one if a project includes more than one language, and zero otherwise.

${ }^{5}$ An additional question concerns the interaction between team dispersion and team familiarity. Espinosa et al. (2007) find that team familiarity and team dispersion (where dispersion is measured with a one if a team has any dispersion, and a zero otherwise) are related to decreased completion time. Repeating each model shown in Table 2 and including the interaction between the team familiarity variables and team dispersion fails to generate any statistically significant coefficients for the interaction effects. Additionally, replacing team dispersion with a dichotomous variable (equal to one if a project is dispersed, and zero otherwise) does not change the reported results for the hypotheses and also does not generate any statistically significant interaction coefficients. It is important to note that in the Espinosa et al. (2007) study team members work together more frequently than in my data ( $\mu$ for team familiarity in their study is 1.80 , while it is 0.40 in my study). It is possible then that the positive interaction effect between team familiarity and team dispersion requires more interactions than I observe in my data. 
Technologies. Finally, Wipro notes the number of technologies that a project encompasses (e.g., client server, e-commerce). I set an indicator to zero if a project addresses one technology, and set it to one otherwise (representing $93 \%$ and $7 \%$ of projects, respectively).

To ease interpretation, I standardize all continuous variables by subtracting the mean from each and then dividing by the standard deviation. Table 1 summarizes statistics for the variables.

*******************************)INSERT TABLE 1 HERE*******************************

\subsection{Empirical Strategy}

Each project outcome - effort deviation, schedule deviation, and defects - is captured by a different variable type (continuous, truncated, and count, respectively). Therefore, I use a different regression model for each analysis. Also, I control for customers' time-invariant characteristics in all the models. To analyze effort deviation, I use a generalized least squares (GLS) random-effects regression model (Stata xtreg, re), as a Hausman test fails to reject the null hypothesis that the random effects model is consistent. I also use heteroskedasticity robust errors, clustered by customer, and remove customers who had only one project in the sample, leaving 562 projects. Since schedule deviation is left-censored at zero, I use a random-effects Tobit regression model - Stata command xttobit, re (Wooldridge 2002). As is the case with effort deviation, the final sample excludes one-project customers, leaving 562 projects for analysis.

My quality measure is a count variable. To control for time-invariant attributes of customers that impact quality and data that exhibit overdispersion, I use a conditional fixed-effects negative binomial model - Stata command xtnbreg, fe (Cameron and Trivedi 1998). Since the model conditions on the total count with a customer, it eliminates all instances having only one observation per group and also those groups for which the dependent variable never varies from zero. Combined with the fact that all projects do not conduct acceptance testing, this yields a final sample of 349 projects. Another empirical approach might have employed hierarchical linear modeling (HLM). HLM can be used properly if data are nested in levels. However, as noted by Reagans et al. (2005), HLM is not appropriate in a setting such as mine, since teams have "overlapping membership," and performance variables are at the team level. 


\section{Results and Analysis}

Table 2 displays results from the models that test the relationship between the performance variables and team familiarity. Note that a negative coefficient means the variable has a positive relationship with performance, for each performance outcome (e.g., a negative coefficient implies fewer expected defects, or better quality). As a baseline, the coefficient for overall team familiarity is negative for all three outcome variables (Columns 1, 5, and 9); however, the result is statistically significant for effort deviation and quality, but not schedule deviation $(\mathrm{p}<0.01, \mathrm{p}<0.05$, and $\mathrm{p}=0.14$, respectively).

********************************INSERT TABLE 2 HERE*******************************

To test Hypothesis 1, I replace the overall familiarity variable with the different-location team familiarity variables. Examining the result for effort deviation in Column 2 shows that the same-location team familiarity coefficient is negative (i.e., related to less deviation) and significantly related to performance $(\mathrm{p}<0.01)$ while the different-location team familiarity coefficient is positive, but not significant at conventional levels $(\mathrm{p}=0.32)$. A chi-squared test rejects the null hypothesis that the two coefficients are equal $\left(\chi^{2}=4.00, \mathrm{p}<0.05\right)$, thus supporting Hypothesis 1 . A one-standard-deviation increase in same-location team familiarity is related to an absolute improvement of 2.3 percentage points of effort deviation, an increase of $49 \%$ as compared to the average-effort deviation. In software services, as in many knowledge-work settings, the primary costs are the workers themselves. Therefore, improvements in effort performance, when coupled with appropriate contract structures (von Branconi and Loch 2004), offer opportunity for direct monetary benefits.

In Column 6, the schedule deviation model, the coefficient for same-location team familiarity is negative and significant $(\mathrm{p}<0.05)$ while the coefficient for different-location team familiarity is not statistically significant $(\mathrm{p}=0.82)$. A chi-squared test fails to reject the null hypothesis that the two coefficients are equal, at conventional levels of significance $\left(\chi^{2}=2.90, p=0.09\right)$. Therefore, Hypothesis 1 is not supported. Finally, Column 10 reveals that the coefficient on same-location team familiarity is negatively and significantly related to project defects $(\mathrm{p}<0.05)$ while the coefficient for different-location team familiarity is positive but not significant $(\mathrm{p}=0.36)$. The coefficients significantly differ $\left(\chi^{2}=4.37\right.$, 
$\mathrm{p}<0.05)$, providing support for Hypothesis 1. A one-standard-deviation increase in same-location team familiarity is related to a $27.2 \%$ decrease in expected defects.

I next examine the results for Hypotheses 2 and 3. In Column 3, the model for effort deviation, the coefficient for hierarchical team familiarity is negative and significant $(p<0.001)$, and the coefficient for horizontal team familiarity is positive and not significant at conventional levels $(\mathrm{p}=0.37)$, thus supporting Hypothesis 2. A chi-squared test rejects the null hypothesis that the coefficients for hierarchical and horizontal team familiarity are equal $\left(\chi^{2}=6.96, p<0.01\right)$. A one-standard-deviation increase in hierarchical team familiarity is related to an absolute improvement of 2.6 percentage points of effort deviation, an increase of $56 \%$ as compared to the average-effort deviation. With respect to schedule deviation (Column 7), I find the coefficient on hierarchical team familiarity negatively and significantly related to performance $(\mathrm{p}<0.01)$ while the coefficient for horizontal team familiarity is positive but not statistically significant at conventional levels $(\mathrm{p}=0.21)$, thus providing support for Hypothesis 2 . The difference between coefficient values is statistically significant $\left(\chi^{2}=6.43, p<0.05\right)$. Finally, with respect to quality, Column 11 shows the coefficient on horizontal team familiarity to be negative and statistically significant $(\mathrm{p}<0.01)$ while the coefficient for hierarchical team familiarity is positive but not significant $(\mathrm{p}=0.45)$, thus supporting Hypothesis 3. A chi-squared test rejects the null hypothesis that the two coefficients are equal $\left(\chi^{2}=4.08, \mathrm{p}<0.05\right)$, A one-standard-deviation increase in horizontal team familiarity is related to a decrease of $28.9 \%$ in expected defects.

\subsection{Evaluating Selection}

Selection bias is an important concern when examining individuals' repeated experience working together. As an organization, Wipro is divided into multiple business units, which consist of industryfocused verticals that typically include 1,000 to 5,000 people each. The marketing, selling, and staffing of projects take place at the vertical level. Project teams are formed not to execute multiple projects in succession, but rather, when a project is completed, the team is dispersed to work on new opportunities. It is not the case, though, that all pairs of individuals across Wipro have the same expected probability of 
working together. Since staffing takes place at the vertical level, it is more likely that individuals within the same vertical will work together repeatedly, as compared to individuals across verticals.

During the sampling period, Wipro was typically supply-constrained-i.e., the utilization rate of personnel was close to the maximum practical value. As such, individuals usually did not wait long between completing a project and being assigned to the next one. Two individuals completing the same project, therefore, were more likely to work together again, compared to any two randomly chosen individuals, since the two on the same project would both have become available for reassignment at the same time. These two points do not, in and of themselves, cause concern; rather, they help to make sure that I observe individuals working together repeatedly, while also generating variance in team familiarity.

A remaining issue is whether project managers can select specific team members? If project managers select team members, they might try to work only with the most skilled team members from prior projects. To evaluate this concern, it is necessary to examine how projects are staffed. The first step in staffing is estimation of the effort and schedule for a project, which is completed by sales personnel at Wipro. The global software services market is competitive and as a result, sales people cannot add undue slack to estimates, or they risk losing a project. The project manager is not assigned to a project until after the customer agrees to the estimates, which provide guidelines for staffing the project. The project manager does not request specific personnel, but rather the staffing group provides individuals who meet the estimate's requirements. However, the project manager does have a formal right to reject a team member. Interviews at Wipro suggest that organizational norms strongly discourage using this power. Ideally, I would examine cases in which managers rejected individuals. However, managers noted that since the phenomenon is uncommon, Wipro does not track this data. Given the supply constraints that Wipro faces in recruiting and training engineers, managers are evaluated on their ability to help struggling engineers. Even so, rejection could prove problematic if used to remove certain members.

To test for this possibility, I use a Cox proportional hazards model to examine two sets of interactions: (1) every dyad of individuals working together and (2) each project manager-team member dyad. Failure is defined as the pair not working together again on the subsequent project. I run the model 
to see if poor performance on any performance variable predicts failure, and find no significant results (results not shown). While these results cannot entirely reject the possibility of selection, they do increase my confidence that selection bias is not the primary reason behind the reported results.

\subsection{Additional Analyses}

Given my desire to establish separate effects for each construct, as well as the different practical and theoretical motivations for relating location and role team familiarity with team performance, I analyzed each independently in the prior models. However, it is also possible to consider them together. In other words, hierarchical team familiarity can be gained with workers in the same or different locations. The same is true for horizontal team familiarity. Therefore, I divide the overall team familiarity variable into four separate variables (hierarchical team familiarity - same location, hierarchical team familiarity - different locations, horizontal team familiarity - same location, and horizontal team familiarity - different locations) and examine the effect on performance (Columns 4, 8, and 12 in Table 2). Results of these models are generally consistent with the separate approaches. For both effort deviation and schedule deviation the coefficient on hierarchical team familiarity - same location, is statistically significant and larger in magnitude than the three other coefficients, although the difference is not significant in all cases. Similarly, with respect to quality (Column 12) the coefficient for horizontal team familiarity - same location has the largest magnitude coefficient and is statistically significant although the different is not significant in all cases.

An additional question relates to the correlation between the different team familiarity measures ( 0.33 and 0.67 for the location and role team familiarity measures, respectively). One possibility is that the correlation may be masking an independent effect of the other familiarity measure that is not statistically significant in the joint model. Therefore, I repeated all analyses for the location and role team familiarity measures, entering only one measure in the model (e.g., only the same-location team familiarity). In all cases, the significant variable (e.g., same-location team familiarity in Table 2, Column 2) remains significant while the variable that is not statistically significant (e.g., different-locations team familiarity in Table 2, Column 2) continues to not be significant. As a final check, I also entered quadratic 
terms for each of the familiarity variables and failed to find statistically significant results.

\subsection{Limitations}

This work has several limitations. First, any non-random assignment of individuals to teams could bias the results. While my interviews and investigatory models find no evidence of selection, I cannot rule out the possibility. A second concern is that team members in different locations might not actually interact. Although my data permit me to observe whether individuals work on the same projects, I do not have information on the time each dyad spends together. Building software is an interdependent process, and interviews at Wipro indicated that team members do interact, at least virtually. Nevertheless, data on the volume and types of interactions that distant dyads have would provide additional insight. Third, the data on geographic dispersion of teams identifies whether individuals are located at the customer location or at one of Wipro's development facilities in India. I do not conclusively know whether team members are located across Wipro facilities within India. Wipro managers noted that at the time this data was collected, teams were not typically spread across facilities in India (rather, workers were collocated at one Indian facility). While the data on team dispersion is more detailed than data used in many other studies (e.g., individual-level data rather than a dichotomous variable to capture whether the team is distributed or not), it would be preferable to have further information. Finally, this study relates to one firm in one industry, so its findings may not generalize to other settings. This limitation is a necessary but undesirable consequence of the rich quantitative data and fieldwork that permitted me to draw together deep knowledge of the firm with large-scale empirical testing of the research questions.

\section{Discussion and Conclusion}

Separating team familiarity to examine differences in individual team members' geographic location and hierarchical role provides additional insight on project team performance. First, my results show that team familiarity gained between workers in the same location has a significantly more positive effect on effort deviation and project quality than team familiarity gained across locations. While the data do not provide opportunity to test the underlying mechanisms, interviews conducted at Wipro's development centers in India do provide additional insight. There appear to be at least three explanations 
for the differential effects: knowledge identification, knowledge sharing, and team dynamics.

When project team members work on the same team at different locations, their ability to identify knowledge within these relationships may be compromised. For example, one project manager at Wipro commented, "When I'm offshore and a team member is onsite, I'm still working with them, but it's different. I don't see the person regularly, I may not visit their location during the entire project. I still know what he is doing, but not the same way I do with a person sitting next to me." In other words, while prior experience may be useful in either the same or different locations case, the increased number of interactions and fidelity of the interactions of the same-location team familiarity is likely to lead to improved knowledge identification within the team, as compared to different-locations - team familiarity.

Differences in knowledge identification based on location highlight an important area for further study. Prior work on problem-solving highlights the key role of context, noting that problem-solvers often must travel to the site of a problem in order to gather information necessary to find a solution (Tyre and von Hippel 1997; Staats, Brunner and Upton 2011). Building on existing work that examines location effects (Festinger et al. 1950; Allen 1977; Kiesler and Cummings 2002), this study's results highlight that not only is task knowledge context-dependent, but so too is relationship knowledge.

Location affects not only the potential knowledge identification benefits from team familiarity, but also a team's ability to share knowledge. Commenting on this, a project engineer explained, "You just don't build the same rapport with your project manager when he's in a different office." In follow-up questioning, he noted the same was true for all team members located in a different office. Also, when asked to explain what he meant by "rapport," he added, "I'm talking about a comfort level. You may not know exactly what he means when he emails you, or you just aren't as comfortable sharing things."

Challenges with knowledge-sharing are related to a third explanation for the diminished role of different-locations team familiarity: team dynamics. Another project engineer explained, "A lot of times on projects, the onsite team thinks the offshore team caused a problem, and the offshore team thinks the onsite team is responsible. You end up with each side blaming the other, and this hurts morale." Workers located in different areas may experience increased conflict and find it difficult to build and sustain trust 
(Jarvenpaa and Leidner 1999; Hinds and Bailey 2003; Hinds and Mortensen 2005). Ideally, prior experience can lead to improved performance. The engineer's quote above suggests that, in the extreme, different-locations team familiarity might lead to worse outcomes (though I do not find that in this study). Future work could explore this concept further.

These potential mechanisms suggest additional areas for further study. The first is to attempt to isolate the relative impact of each mechanism. While each mechanism may contribute to the identified effect, is there one that is dominant? A second question concerns how to improve knowledge identification, knowledge sharing, and team dynamics in situations where familiarity is gained but the workers are in different locations. This question has important theoretical and managerial implications. One possibility is to mix face-to-face and virtual contacts to help a team manage difficulties (Maznevski and Chudoba 2000). Qualitative work suggests that site visits, while expensive, may help dispersed teams take the perspective of their distant colleagues, which may aid performance (Metiu 2006). Additional empirical work should examine when and how face-to-face contact can overcome the noted challenges.

Another approach could be to supplement different-locations team familiarity through a knowledge-management system. Distributed teams that use a knowledge-management system exhibit improved performance compared to distributed teams that do not (Staats, Valentine and Edmondson 2011). Given that a knowledge-management system may include detailed experience profiles of team members, it is possible that the addition of codified knowledge about team members might allow individuals to use their limited tacit knowledge (gained from different-locations team familiarity) to improve team performance. Future work should explore how team familiarity and knowledgemanagement system use interact to affect team performance.

This study also contributes by examining differences in team familiarity as a result of individuals' hierarchical roles. Individuals' roles shape how information is gathered, interpreted, and acted upon (Katz and Kahn 1966). By focusing on hierarchical role, I gain deeper insight into how team familiarity affects performance. I find that hierarchical team familiarity has an effect on project efficiency greater than that of horizontal team familiarity for effort deviation, but not for schedule deviation. Also, I find that 
horizontal team familiarity has an effect on quality greater than that of hierarchical team familiarity.

The interviews conducted at Wipro help to disentangle the effects of role-based familiarity on performance. Delivering a project efficiently depends on structuring and allocating work successfully (Malone and Crowston 1994; Cummings et al. 2009). In addition to the importance of the initial plan, delivering a project efficiently also depends on in-process updates and course corrections (Wheelwright and Clark 1992). These, in turn, depend on a project manager's ability to identify knowledge within a team, access that knowledge, and then apply it to the task at hand.

Describing the impact of hierarchical team familiarity, one project manager commented, "After I've worked with people, I know how they work. I learn their strengths and weaknesses. So, for example, I know one person is good for technical, not customer-facing, roles. You don't look at people as being a risk, but it is." With prior experience working together, a project manager can identify important knowledge (an individual's "strengths and weaknesses"), and then can apply the knowledge to make better decisions (in this case, for work allocation).

One challenge for managers is getting team members to quickly reveal when they encounter a problem (Edmondson 1996). This issue can be particularly challenging in a knowledge-work setting, where much of the work takes place in an individual's head so it is difficult to visually identify problems (Staats et al. 2011). Hierarchical team familiarity may help to address this challenge by improving the knowledge-sharing that takes place within a team. A project manager explained, "When you work with the same person, you have rapport; the team is comfortable, so they share what is going on behind the scenes. Everything is transparent. The team trusts you more and then you don't get surprises." Providing additional support to the knowledge-sharing point, another project manager added:

For a project to be successful, you need coordination from the project manager to team members. In the Indian context, people always say "yes," even when they know they can't accomplish a task. People I've worked with are more forthcoming. Not only do they have a better understanding of what I want, they know how I will react. They grow in confidence and share more information. It takes some time to build this trust, but when it is there, they will share more about timelines [a key input to project efficiency] and will tell me when they think something isn't reasonable.

Thus, hierarchical familiarity may lead to improved communication and sharing of information, 
increasing the likelihood that a manager will learn and then be in a position to respond to issues that might otherwise remain hidden. Future work should seek to understand in more detail the mechanisms by which hierarchical team familiarity affects project efficiency.

In addition to the positive relationship of hierarchical team familiarity to project efficiency, I find that hierarchical familiarity has a greater effect on effort deviation than does horizontal team familiarity, and that hierarchical team familiarity does not relate with quality in a statistically significant way. This suggests that project efficiency may possess characteristics that respond particularly well to hierarchical team familiarity. I posit that a key detail may be the measures' observability in process. Wipro has tools in place to help a project manager track how a project is going with respect to effort and schedule. These tools are no substitutes for team familiarity, but rather enhance the value of team familiarity as they provide information at a project level, allowing managers to make better decisions with respect to individuals' actions (e.g., allocating to an individual responsibility to complete a certain part of the code in a project). Familiarity between the project manager and team members can have numerous benefits, but these may be most useful when performance is observable in process, since then project managers can do what their titles suggest: manage projects. For example, if engineers feel psychologically safe to share their understanding of what is taking place, but the manager cannot act on the information quickly enough or at all, then this value of team familiarity may be lost. While effort and schedule performance can be observed in process, tracking project quality on a real-time basis may not be possible.

This study also shows that horizontal team familiarity is positively and significantly related to project quality. Developing quality output depends on significant low-level interactions within a team. Team members must effectively coordinate activities so their individual outputs seamlessly integrate. Describing this process, a project manager noted:

It can really make a difference when team members have worked together. They know what to expect from each other, and they know who to talk to when they find a problem [in the code]. For most problems, the person who wrote the code knows best how to fix it, so if team members can just work together to figure it out, then it's best.

Thus, when engineers become more familiar with team members, they may not only increase the 
likelihood of identifying the right person from whom to seek help, but they also may be more likely to approach that person, given the increased comfort level (Hofmann et al. 2009).

Another key aspect of quality in a software context involves detection of errors. One approach for detecting errors is through the use of the industry-standard practice of peer review, by which team members examine and test one another's code. While peer review and testing offer potential for improved performance, the benefit may be compromised by either ineffective testing or unwillingness to confront other team members about problems. A project manager explained:

Quality happens with the team. Unless there is proper communication within the team, quality won't come in. With experience together, engineers do a better job of peer testing and peer review. You get more sharing of knowledge within the team. All of this leads to a higher-quality output.

Explaining how horizontal team familiarity aids the reviewing process, a team member added:

Peer relationships in teams can have a strong effect on performance. The engineer knows how the other person writes code. He knows his [the other engineer's] style, his strong points, and the common mistakes that he makes. When engineers have worked together previously, they can go straight to the other person to talk about a problem or an issue with a dependency. Experience together really helps in massaging egos. They can communicate data much more effectively. All of this helps us to catch mistakes sooner, and to help solve problems when we find them.

Thus, when team members have experience working together, they may seek help more effectively within the team and better identify errors and work with team members to address them.

The empirical models reveal that horizontal team familiarity has a more significant, positive effect on quality than does hierarchical team familiarity. Project engineers' close proximity to the code may help them to effectively coordinate lower-level problem-solving. Engineers write the code, therefore likely have the most knowledge about the code itself. Given the need for seamless integration between workers to deliver quality output, the manager may be, in some cases, an unnecessary middleman. In other words, if one engineer is having an issue with another part of the system designed by a second engineer while trying to develop quality software, as often is the case, it may work best for the two engineers to connect directly rather than rely on the project manager to facilitate communications. While hierarchical team familiarity might still lead to improved quality (e.g., due to a manager's discovering that a worker cannot solve a given problem), this effect is likely dominated by horizontal team familiarity. 
Future work should build on studies examining front-line problem solving (e.g., Tucker 2007) to understand conditions where different types of familiarity may dominate (e.g., observability in process).

It is important to note that both sets of results mean that managers may be faced with a tradeoff of short-term project performance versus long-term learning or flexibility. Taken to the extreme, the results presented suggest that performance may be best when workers gain familiarity with each other all in the same place, project managers and engineers have prior experience together (for improved project efficiency), and/or project engineers have experience together (for better project quality). However, project needs, staff availability, or customer requirements may necessitate project teams' being staffed across different locations. For example, since the median project length in the dataset is six months, gaining same-location familiarity requires team members to be collocated at the site for this period of time, on average. The optimal balancing of these short- and long-term benefits is both highly contextdependent and beyond the scope of this paper. However, what the results do suggest is that not only should theory on team familiarity account for which team members work together under what conditions, but, when possible, managers should allocate project personnel with differing types of familiarity in mind.

This paper has taken the perspective that team familiarity offers performance benefits. One important question is what substitutes may exist for team familiarity so that low-familiarity teams can still deliver excellent performance. Future work should seek to answer this question. An additional question is whether team familiarity might worsen performance in ways not measured in this study. For example, one question for future research to consider is whether teams with prior experience working together make better or worse ethical decisions. The former is possible, as team members may feel more psychologically safe and willing to bring up concerns about others' behavior; conversely, familiarity could help unethical decision-making to spread throughout a team (Gino, Ayal and Ariely 2009). In addition, while team familiarity may improve the quality of behavior being monitored, it also is possible that team familiarity could decrease the total amount of monitoring done: under certain conditions, peers might decide that an individual is trustworthy and therefore does not need monitoring. While this assessment might be accurate, it also might increase the probability of catastrophic failure due to lowered total monitoring. 
Altogether, future work should explore the beneficial and negative effects of team familiarity.

This paper also has important implications for operations strategy. First, it sheds light on the microfoundations of organizational capability. While it is widely recognized that the ability to solve problems reliably with bundles of routines can lead to competitive advantage (Nelson and Winter 1982), less is known about the microfoundations of such capabilities (Helfat 2000). If a capability consists of the accumulated knowledge of an organization and its members (Dosi, Nelson and Winter 2000), then any experience offering new knowledge may add to capability evolution. Thus, experience gained from repeated interactions between organization members may be important to organizational capability development. As noted by Argote and Ingram (2000), however, these interactions have seldom been examined in this light. This paper shows that capabilities are not simply aggregations of individual skills and experience, but rather depend, in part, on connections between individuals developed through work experience: team familiarity.

Also, this study's results offer insight into competitive advantage. To maintain a competitive advantage, an organization's capabilities must be difficult to copy (Barney 1991). Hatch and Dyer (2004) note that "human capital is most valuable and most inimitable when it is firm-specific (p. 1155)." Research on firm-specific experience supports the inimitability argument, as Huckman and Pisano (2006) find that the quality of surgeon performance improves with cumulative experience, but only when surgeries are conducted at the same hospital. They suggest the mechanism is familiarity with firm-specific assets, such as team members. Viewed in light of that work, this study's findings show how one type of firm-specific experience, team familiarity, may improve the effectiveness of an organizational capability, thus contributing to building a sustainable competitive advantage.

My findings also offer opportunities for managerial action. The advice to increase all team familiarity is easy to understand, but difficult to apply operationally. Due to factors such as turnover, promotions, and differing project skill requirements, it is difficult to keep all team members together over time. Identifying which relationships matter in what circumstances offers a valuable managerial lever to affect team performance. In other words, my results suggest that the type of familiarity most important to 
an organization may depend on the organization's strategy and objectives. By taking a more fine-grained view of experience accumulation, organizations may further improve knowledge-workers' productivity. Since learning is path-dependent and previous experience may determine subsequent action, explicitly tracking, understanding, and managing the accumulation of experience are all important. Incorporating information about experience into internal operations is difficult and requires significant action and investment (e.g., tracking experience, creating assignment algorithms that balance a firm's and individuals' needs, etc.), but doing so may generate opportunities to create an operations-based competitive advantage (Hayes and Pisano 1996).

In conclusion, it has been asserted that successfully managing knowledge work and workers is a primary competitive differentiator among firms (Drucker 1999; Hopp, Iravani and Liu 2009). In this paper, I have examined a fast-moving, knowledge-based industry to gain insight into how team composition can affect knowledge-work productivity. I find that it is important to examine not just whether team members have worked together, but which team members have done so, and under what conditions. These distinctions are important, as the varying impacts of different interactions on team performance help to isolate mechanisms through which team familiarity affects performance. 
Table 1. Summary statistics and correlation table of dependent, independent, and control variables of interest ( $n=562$, except for post-delivery defects, where $n=349$ ).

\begin{tabular}{|c|c|c|c|c|c|c|c|c|c|c|c|c|c|c|}
\hline Variable & Mean & $\boldsymbol{\sigma}$ & 1 & 2 & 3 & 4 & 5 & 6 & 7 & 8 & 9 & 10 & 11 & 12 \\
\hline 1. Effort Deviation & -4.70 & 19.28 & & & & & & & & & & & & \\
\hline 2. Schedule Deviation & 1.23 & 8.84 & 0.64 & & & & & & & & & & & \\
\hline 3. Post-Delivery Defects & 26.5 & 111.6 & 0.09 & 0.03 & & & & & & & & & & \\
\hline 4. Overall Team Familiarity ${ }^{\mathrm{a}}$ & 0.40 & 0.49 & -0.10 & -0.07 & -0.10 & & & & & & & & & \\
\hline 5. Same-Location Team Familiarity ${ }^{\mathrm{a}}$ & 0.31 & 0.43 & -0.11 & -0.11 & -0.10 & 0.92 & & & & & & & & \\
\hline 6. Different-Location Team Familiarity ${ }^{\text {a }}$ & 0.08 & 0.14 & -0.03 & -0.04 & 0.01 & 0.51 & 0.33 & & & & & & & \\
\hline 7. Hierarchical Team Familiarity ${ }^{\mathrm{a}}$ & 0.44 & 0.54 & -0.11 & -0.11 & -0.07 & 0.85 & 0.81 & 0.41 & & & & & & \\
\hline 8. Horizontal Team Familiarity ${ }^{a}$ & 0.25 & 0.34 & -0.07 & -0.07 & -0.14 & 0.79 & 0.74 & 0.40 & 0.67 & & & & & \\
\hline 9. Task Change ${ }^{\mathrm{a}}$ & 0.19 & 0.27 & 0.20 & 0.10 & 0.22 & -0.06 & -0.04 & 0.04 & -0.01 & -0.07 & & & & \\
\hline 10. Team Role Experience ${ }^{a}$ & 1.24 & 0.57 & -0.05 & -0.01 & -0.08 & 0.22 & 0.22 & 0.11 & 0.20 & 0.21 & -0.04 & & & \\
\hline 11. Contract Type & 0.68 & 0.47 & -0.05 & 0.09 & -0.12 & 0.09 & 0.09 & 0.10 & 0.07 & 0.05 & -0.16 & 0.16 & & \\
\hline 12. Team Dispersion ${ }^{\mathrm{a}}$ & 0.15 & 0.14 & -0.08 & -0.12 & 0.03 & -0.04 & -0.12 & 0.30 & -0.08 & -0.06 & -0.02 & 0.14 & 0.10 & \\
\hline 13. Complexity ${ }^{a}$ & 0.00 & 1.72 & 0.07 & -0.01 & 0.34 & -0.20 & -0.21 & -0.09 & -0.15 & -0.14 & 0.19 & -0.02 & -0.16 & 0.17 \\
\hline
\end{tabular}

(a) In models this variable is standardized by subtracting the mean and dividing by the standard deviation. Summary statistics are for the unstandardized variable.

Note. Bold denotes significance of less than $5 \%$. 
Table 2. Summary results of the regression of effort deviation, schedule deviation, and post-delivery defects on team familiarity $(n=562,562$, and 349 , respectively).

\begin{tabular}{|c|c|c|c|c|c|c|c|c|c|c|c|c|}
\hline \multirow[t]{2}{*}{1} & \multicolumn{4}{|c|}{$\begin{array}{l}\text { Dependent Variable: } \\
\text { Effort Deviation }\end{array}$} & \multicolumn{4}{|c|}{$\begin{array}{l}\text { Dependent Variable: } \\
\text { Schedule Deviation }\end{array}$} & \multicolumn{4}{|c|}{$\begin{array}{l}\text { Dependent Variable: } \\
\text { Post-Delivery Defects }\end{array}$} \\
\hline & $(1)$ & (2) & (3) & (4) & (5) & (6) & (7) & (8) & (9) & (10) & (11) & (12) \\
\hline Overall Team Familiarity & $\begin{array}{c}-1.832 * * \\
(0.648)\end{array}$ & & & & $\begin{array}{l}-3.450 \\
(2.316)\end{array}$ & & & & $\begin{array}{l}-0.236^{*} \\
(0.109)\end{array}$ & & & \\
\hline Same-Location Team Familiarity & & $\begin{array}{c}-2.323^{* *} \\
(0.894)\end{array}$ & & & & $\begin{array}{l}-6.428^{*} \\
(2.699)\end{array}$ & & & & $\begin{array}{l}-0.317^{*} \\
(0.134)\end{array}$ & & \\
\hline Different-Location Team Familiarity & & $\begin{array}{c}0.840 \\
(0.852)\end{array}$ & & & & $\begin{array}{c}0.538 \\
(2.332)\end{array}$ & & & & $\begin{array}{c}0.086 \\
(0.094)\end{array}$ & & \\
\hline Hierarchical Team Familiarity & & & $\begin{array}{l}-2.619^{* * *} \\
(0.768)\end{array}$ & & & & $\begin{array}{c}-10.091 * * \\
(3.247)\end{array}$ & & & & $\begin{array}{c}0.094 \\
(0.124)\end{array}$ & \\
\hline Horizontal Team Familiarity & & & $\begin{array}{c}0.520 \\
(0.573)\end{array}$ & & & & $\begin{array}{l}3.297 \\
(2.600)\end{array}$ & & & & $\begin{array}{l}-0.341 * * \\
(0.120)\end{array}$ & \\
\hline $\begin{array}{l}\text { Hierarchical Team Familiarity - } \\
\text { Same Location }\end{array}$ & & & & $\begin{array}{c}-2.765 * * \\
(0.977)\end{array}$ & & & & $\begin{array}{l}-7.624 * \\
(3.468)\end{array}$ & & & & $\begin{array}{c}0.033 \\
(0.158)\end{array}$ \\
\hline $\begin{array}{l}\text { Hierarchical Team Familiarity - } \\
\text { Different Location }\end{array}$ & & & & $\begin{array}{l}-0.089 \\
(0.805)\end{array}$ & & & & $\begin{array}{l}-5.072 \\
(3.032)\end{array}$ & & & & $\begin{array}{l}0.135 \\
(0.077)\end{array}$ \\
\hline $\begin{array}{l}\text { Horizontal Team Familiarity - Same } \\
\text { Location }\end{array}$ & & & & $\begin{array}{c}0.171 \\
(0.679)\end{array}$ & & & & $\begin{array}{l}4.219 \\
(2.898)\end{array}$ & & & & $\begin{array}{l}-0.418^{*} \\
(0.209)\end{array}$ \\
\hline $\begin{array}{l}\text { Horizontal Team Familiarity - } \\
\text { Different Location }\end{array}$ & & & & $\begin{array}{c}0.756 \\
(0.660)\end{array}$ & & & & $\begin{array}{c}1.064 \\
(2.138)\end{array}$ & & & & $\begin{array}{l}-0.042 \\
(0.086)\end{array}$ \\
\hline Task Change $^{\mathrm{a}}$ & $\begin{array}{l}3.693^{*} \\
(1.710)\end{array}$ & $\begin{array}{l}3.634^{*} \\
(1.718)\end{array}$ & $\begin{array}{l}3.764 * \\
(1.715)\end{array}$ & $\begin{array}{l}3.668^{*} \\
(1.721)\end{array}$ & $\begin{array}{l}3.937^{*} \\
(1.706)\end{array}$ & $\begin{array}{l}3.819^{*} \\
(1.674)\end{array}$ & $\begin{array}{l}4.264 * \\
(1.708)\end{array}$ & $\begin{array}{l}4.164 * \\
(1.726)\end{array}$ & $\begin{array}{c}0.038 \\
(0.077)\end{array}$ & $\begin{array}{c}0.017 \\
(0.078)\end{array}$ & $\begin{array}{c}0.041 \\
(0.078)\end{array}$ & $\begin{array}{c}0.025 \\
(0.079)\end{array}$ \\
\hline Team Role Experience $^{\mathrm{a}}$ & $\begin{array}{l}-1.079 \\
(1.083)\end{array}$ & $\begin{array}{l}-0.997 \\
(1.069)\end{array}$ & $\begin{array}{l}-1.032 \\
(1.095)\end{array}$ & $\begin{array}{l}-1.082 \\
(1.057)\end{array}$ & $\begin{array}{l}-1.257 \\
(1.920)\end{array}$ & $\begin{array}{l}-0.764 \\
(1.889)\end{array}$ & $\begin{array}{l}-0.959 \\
(1.908)\end{array}$ & $\begin{array}{l}-1.132 \\
(1.903)\end{array}$ & $\begin{array}{l}-0.131 \\
(0.090)\end{array}$ & $\begin{array}{l}-0.113 \\
(0.091)\end{array}$ & $\begin{array}{l}-0.139 \\
(0.090)\end{array}$ & $\begin{array}{l}-0.127 \\
(0.091)\end{array}$ \\
\hline Contract Type & $\begin{array}{c}0.580 \\
(1.998)\end{array}$ & $\begin{array}{c}0.574 \\
(2.008)\end{array}$ & $\begin{array}{c}0.717 \\
(1.986)\end{array}$ & $\begin{array}{c}0.685 \\
(2.028)\end{array}$ & $\begin{array}{c}12.996^{* * *} \\
(4.429)\end{array}$ & $\begin{array}{c}12.617^{* * *} \\
(4.327)\end{array}$ & $\begin{array}{c}13.098^{* *} \\
(4.343)\end{array}$ & $\begin{array}{c}13.230^{\text {** }} \\
(4.369)\end{array}$ & $\begin{array}{c}0.326 \\
(0.189)\end{array}$ & $\begin{array}{c}0.321 \\
(0.189)\end{array}$ & $\begin{array}{c}0.326 \\
(0.189)\end{array}$ & $\begin{array}{c}0.325 \\
(0.189)\end{array}$ \\
\hline Team Dispersion $^{a}$ & $\begin{array}{l}-0.237 \\
(0.991)\end{array}$ & $\begin{array}{l}-0.704 \\
(1.102)\end{array}$ & $\begin{array}{l}-0.326 \\
(0.990)\end{array}$ & $\begin{array}{l}-0.585 \\
(1.008)\end{array}$ & $\begin{array}{l}-6.384 * * \\
(2.268)\end{array}$ & $\begin{array}{c}-6.789^{* *} \\
(2.295)\end{array}$ & $\begin{array}{l}-6.792 * * \\
(2.260)\end{array}$ & $\begin{array}{l}-6.378^{* *} \\
(2.310)\end{array}$ & $\begin{array}{l}-0.032 \\
(0.080)\end{array}$ & $\begin{array}{l}-0.074 \\
(0.085)\end{array}$ & $\begin{array}{l}-0.027 \\
(0.080)\end{array}$ & $\begin{array}{l}-0.061 \\
(0.083)\end{array}$ \\
\hline Complexity $^{a}$ & $\begin{array}{c}0.639 \\
(0.527)\end{array}$ & $\begin{array}{c}0.698 \\
(0.523)\end{array}$ & $\begin{array}{c}0.704 \\
(0.518)\end{array}$ & $\begin{array}{c}0.720 \\
(0.532)\end{array}$ & $\begin{array}{c}1.507 \\
(1.177)\end{array}$ & $\begin{array}{c}1.364 \\
(1.148)\end{array}$ & $\begin{array}{l}1.356 \\
(1.144)\end{array}$ & $\begin{array}{c}1.574 \\
(1.172)\end{array}$ & $\begin{array}{c}0.229 * * * \\
(0.051)\end{array}$ & $\begin{array}{c}0.255 * * * \\
(0.054)\end{array}$ & $\begin{array}{c}0.242 * * * \\
(0.051)\end{array}$ & $\begin{array}{c}0.229 * * * \\
(0.052)\end{array}$ \\
\hline Constant & $\begin{array}{l}-4.784 * \\
(2.248)\end{array}$ & $\begin{array}{l}-4.447 \\
(2.277)\end{array}$ & $\begin{array}{l}-5.134 * \\
(2.230)\end{array}$ & $\begin{array}{l}-4.781^{*} \\
(2.208)\end{array}$ & $\begin{array}{c}-44.181 * * * \\
(9.498)\end{array}$ & $\begin{array}{c}-43.282^{* * * *} \\
(9.401)\end{array}$ & $\begin{array}{c}-46.946^{* * * *} \\
(9.631)\end{array}$ & $\begin{array}{c}-46.515^{* * * *} \\
(9.650)\end{array}$ & $\begin{array}{c}-1.764 * * * \\
(0.342)\end{array}$ & $\begin{array}{c}-1.703 * * * \\
(0.345)\end{array}$ & $\begin{array}{c}-1.753^{* * * *} \\
(0.342)\end{array}$ & $\begin{array}{c}-1.766^{* * * *} \\
(0.350)\end{array}$ \\
\hline Observations & 562 & 562 & 562 & 562 & 562 & 562 & 562 & 562 & 349 & 349 & 349 & 349 \\
\hline Overall $R^{2}$ & 0.1872 & 0.2149 & 0.1879 & 0.1819 & - & - & - & - & - & - & - & - \\
\hline Log Pseudolikelihood & - & - & - & - & -485.4 & -483.2 & -480.2 & -482.0 & -725.5 & -724.8 & -723.0 & -722.9 \\
\hline Wald chi-squared & $49.1661 * * *$ & $49.8467 * * *$ & $58.7991 * * *$ & $53.5284 * * *$ & $36.1783^{* * * *}$ & $39.6350 * * *$ & $41.6758 * * *$ & $39.6522 * * *$ & $58.2656 * * *$ & $58.2982 * * *$ & $64.3477 * * *$ & $60.0185^{* * * *}$ \\
\hline
\end{tabular}

Notes: ****and **** denote significance at the $5 \%, 1 \%$, and $0.1 \%$ levels, respectively. Effort deviation models are GLS random-effects models with heteroskedasticity robust standard errors, clustered on the customer. Schedule deviation models are random-effects Tobit models. Post-delivery defect models are conditional fixed effects, negative binomial regression models that condition on the customer. Models include, but results are not shown, for the indicator variables for number of software languages, type of software language, number of technologies, and start year.

${ }^{a}$ Variable is standardized by subtracting the mean and dividing by the standard deviation. 


\section{References}

Allen, T. J. (1977). Managing the Flow of Technology. Cambridge, MA, MIT Press.

Argote, L., S. L. Beckman and D. Epple (1990). "The persistence and transfer of learning in industrial settings." Management Sci. 36(2): 140-154.

Argote, L. and P. Ingram (2000). "Knowledge transfer: A basis for competitive advantage in firms." Organ. Behav. Human Decision Proc. 82(1): 150-169.

Armstrong, D. J. and P. Cole (2002). Managing distances and differences in geographically distributed work groups. Distributed Work. P. J. Hinds and S. Kiesler. Cambridge, MIT Press: 167-186.

Arrow, H. and J. E. McGrath (1995). Membership dynamics in groups at work: A theoretical framework. Research in Organizational Behavior. B. Staw and L. Cummings. Greenwich, CT, JAI. 17: 373-411.

Barney, J. (1991). "Firm resources and sustained competitive advantage." J. of Management 17(1): 99.

Beck, K. and B. Boehm (2003). "Agility through discipline: A debate." IEEE Computer 36(6): 44-46.

Boehm, B. (1981). Software Engineering Economics. New York, Prentice Hall.

Boh, W. F., S. A. Slaughter and J. A. Espinosa (2007). "Learning from experience in software development: A multilevel analysis." Management Sci. 53(8): 1315-1331.

Brooks, F. (1975). The Mythical Man-Month: Essays on Software Engineering. New York, Addison-Wesley.

Cameron, A. C. and P. K. Trivedi (1998). Regression Analysis of Count Data. New York, Cambridge Univ Press.

Cramton, C. D. (2001). "The mutual knowledge problem and its consequences for dispersed collaboration." Organ. Sci. 12(3): 346.

Cummings, J. N. (2004). "Work groups, structural diversity, and knowledge sharing in a global organization." Management Sci. 50(3): 352-364.

Cummings, J. N., J. A. Espinosa and C. K. Pickering (2009). "Crossing spatial and temporal boundaries in globally distributed projects: A relational model of coordination delay." Info. Systems Res. 20(3): 420-439.

Dosi, G., R. R. Nelson and S. G. Winter (2000). The Nature and Dynamics of Organizational Capabilities. London, Oxford University Press.

Drucker, P. F. (1999). Management Challenges for the 21st Century. New York, HarperBusiness.

Edmondson,A.(1999)."Psychological safety and learning behavior in work teams."Admin. Sci. Quart.44(2):350-383.

Edmondson, A. C. (1996). "Learning from mistakes is easier said than done: Group and organizational influences on the detection and correction of human error." Journal of Applied Behavioral Science 32(1): 5-28.

Edmondson, A. C. and I. A. Nembhard (2009). "Product development and learning in project teams: The challenges are the benefits." J. of Product Innovation Management 26(2): 123-138.

Espinosa, J. A., S. A. Slaughter, R. E. Kraut and J. D. Herbsleb (2007). "Familiarity, complexity, and team performance in geographically distributed software development." Organ. Sci. 18(4): 613-630.

Faraj, S. and L. Sproull (2000). "Coordinating expertise in software development teams." Management Sci. 46(12): 1554-1568.

Festinger, L., S. Schachter and K. W. Back (1950). Social Pressures in Informal Groups. New York, Harper.

Gibson, C. B. and S. G. Cohen (2003). Virtual Teams That Work. San Francisco, Jossey-Bass.

Gino, F., S. Ayal and D. Ariely (2009). "Contagion and differentiation in unethical behavior: The effect of one bad apple on the barrel." Psychological Science 20(3): 393-398.

Gokpinar, B., W. J. Hopp and S. M. R. Iravani (2010). "The impact of product architecture and organization structure on efficiency and quality of complex product development." Management Sci. 56(3): 468-484.

Goodman, P. S. and D. P. Leyden (1991). "Familiarity and group productivity." J. of Applied Psychology 76(4): 578-586.

Gruenfeld, D. H., E. A. Mannix, K. Y. Williams and M. A. Neale (1996). "Group composition and decision making." Organ. Behav. Human Decision Proc. 67(1): 1-15.

Haas, M. R. and M. T. Hansen (2007). "Different knowledge, different benefits: toward a productivity perspective on knowledge sharing in organizations." Strategic Management J. 28(11): 1133-1153.

Harrison, D. A., S. Mohammed, J. E. McGrath, A. T. Florey and S. W. Vanderstoep (2003). "Time matters in team performance." Personnel Psychology 56(3): 633-669.

Harrison, D. A., K. Price, J. Gavin and A. T. Florey (2002). "Time, teams, and task performance: Changing effects of surface- and deep-level diversity on group functioning." Acad. of Management J. 45(5): 1029-1045.

Hatch, N. W. and J. H. Dyer (2004). "Human capital and learning as a source of sustainable competitive advantage." Strategic Management J. 25(12): 1155-1178.

Hayes, R. H. and G. P. Pisano (1996). "Manufacturing strategy: At the intersection of two paradigm shifts." Prod. Oper. Manag. 5(1): 25-41. 
Helfat, C. E. (2000). "Guest editor's introduction to the special issue: The evolution of firm capabilities." Strategic Management J. 21(10/11): 955-959.

Herroelen, W. (2005). "Project scheduling—Theory and practice." Prod. Oper. Manag. 14(4): 413-432.

Hinds, P. and S. Kiesler (2002). Distributed Work. Boston, MIT Press.

Hinds, P. J. and D. E. Bailey (2003). "Out of sight, out of sync: Understanding conflict in distributed teams." Organ. Sci. 14(6): 615-632.

Hinds, P. J., K. M. Carley, D. Krackhardt and D. Wholey (2000). "Choosing work group members: Balancing similarity, competence, and familiarity." Organ. Behav. Human Decision Proc. 81(2): 226-251.

Hinds, P. J. and M. Mortensen (2005). "Understanding conflict in geographically distributed teams: The moderating effects of shared identity, shared context, and spontaneous communication." Organ. Sci. 16(3): 290-307.

Hofmann, D. A., Z. Lei and A. M. Grant (2009). "Seeking help in the shadow of doubt: The sensemaking processes underlying how nurses decide whom to ask for advice." J. of Applied Psychology 94(5): 1261-1274.

Hofmann, D. A., F. P. Morgeson and S. J. Gerras (2003). "Climate as a moderator of the relationship between leader-member exchange and content specific citizenship." J. of Applied Psychology 88(1): 170-178.

Hopp, W. J., S. M. R. Iravani and F. Liu (2009). "Managing white-collar work: An operations-oriented survey." Prod. Oper. Manag. 18(1): 1-32.

Huckman, R. S. and G. P. Pisano (2006). "The firm specificity of individual performance: Evidence from cardiac surgery." Management Sci. 52(4): 473-488.

Huckman, R. S. and B. R. Staats (Forthcoming). "Fluid tasks and fluid teams: The impact of diversity in experience and team familiarity on team performance." Manufacturing Service Oper. Management.

Huckman, R. S., B. R. Staats and D. M. Upton (2009). "Team familiarity, role experience, and performance: Evidence from Indian software services." Management Sci. 55(1): 85-100.

Jarvenpaa, S. L. and D. E. Leidner (1999). "Communication and trust in global virtual teams." Organ. Sci. 10(6): 791-815.

Jensen, M. C. and K. Meckling (1976). "Theory of the firm: Managerial behavior, agency costs and ownership structure." Journal of Financial Economics 3: 305-360.

Kandel, E. and E. P. Lazear (1992). "Peer pressure and partnerships." J. of Polticial Econ. 100(4): 801-817.

Kane, A. A., L. Argote and J. M. Levine (2005). "Knowledge transfer between groups via personnel rotation: Effects of social identity and knowledge quality." Organ. Behav. Human Decision Proc. 96(1): 56-71.

Katz, D. and R. L. Kahn (1966). The Social Psychology of Organizations. New York, Wiley.

Kiesler, S. and J. Cummings (2002). What do we know about proximity and distance in work groups? . Distributed Work. P. Hinds and S. Kiesler. Cambridge, MIT Press: 57-80.

Lapré, M. A., A. S. Mukherjee and L. N. V. Wassenhove (2000). "Behind the learning curve: Linking learning activities to waste reduction." Management Sci. 46(5): 597-611.

Lee, F. (1997). "When the going gets tough, do the tough ask for help? Help seeking and power motivation in organizations." Organ. Behav. Human Decision Proc. 72(3): 336-363.

Lee, F., A. C. Edmondson, S. Thomke and M. Worline (2004). "The mixed effects of inconsistency on experimentation in organizations." Organ. Sci. 15(3): 310-326.

Leonardi, P. M. (2007). "Activating the informational capabilities of information technology for organizational change." Organ. Sci. 18(5): 813-831.

Lewis, K. (2003). "Measuring transactive memory systems in the field: Scale development and validation." J. of Applied Psychology 88(4): 587-604.

Lewis, K., D. Lange and L. Gillis (2005). "Transactive Memory Systems, learning, and learning transfer." Organ. Sci. 16(6): 581-598.

Liang, D. W., R. Moreland and L. Argote (1995). "Group versus individual training and group performance: the mediating role of transactive memory." Personality and Social Psychology Bulletin 21(4): 384-393.

Littlepage, G., W. Robison and K. Reddington (1997). "Effects of task experience and group experience on group performance, member ability, and recognition of expertise." Organ. Behav. Human Decision Proc. 69(2): 133-147.

Majchrzak, A., A. Malhotra and R. John (2005). "Perceived individual collaboration know-how development through information technology-enabled contextualization." Info. Systems Res. 16(1): 9 - 27.

Malone, T. W. and K. Crowston (1994). "The interdisciplinary study of coordination." ACM Computing Surveys 26(1): 87-119.

Marx, K. and F. Engels (2002). The Communist Manifesto. London, Penguin Books.

Maznevski, M. L. and K. M. Chudoba (2000). "Bridging space over time: Global virtual team dynamics and effectiveness." Organ. Sci. 11(5): 473-492. 
Metiu, A. (2006). "Owning the code: Status closure in distributed groups." Organ. Sci. 17(4): 418-435.

Monteverde, K. (1995). "Technical dialog as an incentive for vertical integration in the semiconductor industry." Management Sci. 41(10): 1624-1638.

Moreland, R., L. Argote and R. Krishnan (1998). Training people to work in groups. Theory and Research on Small Groups. R. Tindale and L. Heath. New York, Plenum Press: 37-60.

Narayanan, S., S. Balasubramanian and J. M. Swaminathan (2009). "A matter of balance: Specialization, task variety, and individual learning in a software maintenance environment." Management Sci. 55(11): 18611876.

Narayanan, S., S. Balasubramanian and J. M. Swaminathan (Forthcoming). "Managing outsourced software projects: An analysis of project performance and customer satisfaction." Prod. Oper. Manag.

Nelson, R. R. and S. G. Winter (1982). An Evolutionary Theory of Economic Change. Cambridge, Belknap Press.

O'Leary, M. B. and J. N. Cummings (2007). "The spatial, temporal, and configurational characteristics of geographic dispersion in teams." MIS Quart. 31(3): 433-452.

O'Leary, M. B. and M. Mortensen (2010). "Go (con)figure: Subgroups, imbalance, and isolates in geographically dispersed teams." Organ. Sci. 21(1): 115-131.

Reagans, R., L. Argote and D. Brooks (2005). "Individual experience and experience working together: Predicting learning rates from knowing who knows what and knowing how to work together." Management Sci. 51(6): 869-881.

SEI (2001). Capability Maturity Model Integration (CMMI), Version 1.1. Pittsburgh, PA, Software Engineering Institute, Carnegie Mellon University.

Siemsen, E., A. V. Roth, S. Balasubramanian and G. Anand (2009). "The influence of psychological safety and confidence in knowledge on employee knowledge sharing." Manufacturing Service Oper. Management 11(3): 429-447.

Sorenson, O. and P. G. Audia (2000). "The social structure of entrepreneurial activity: Geographic concentration of footwear production in the United States, 1940-1989." American J. of Soc. 106(2): 424-461.

Sosa, M. E. (Forthcoming). "Where do creative interactions come from?." Organ. Sci.

Sosa, M. E., S. D. Eppinger and C. M. Rowles (2004). "The misalignment of product architecture and organizational structure in complex product development." Management Sci. 50(12): 1674-1689.

Staats, B. R., D. J. Brunner and D. M. Upton (Forthcoming). "Lean principles, learning, and knowledge work: Evidence from a software services provider." J. of Oper. Management.

Staats, B. R., M. A. Valentine and A. C. Edmondson (2011). "Using what we know: Turning organizational knowledge into team performance." Harvard Business School Working Paper.

Steiner, I. D. (1972). Group Process and Productivity. New York, Academic Press.

Stewart, D. M. (2003). "Piecing together service quality." Prod. Oper. Manag. 12(2): 246-265.

Szulanski, G. (1996). "Exploring internal stickiness: Impediments to the transfer of best practice within the firm." Strategic Management J. 17(Special Issue: Knowledge and the Firm): 27-43.

Taylor, F. W. (1911). The Principles of Scientific Management. New York, Harper \& Brothers.

Tucker, A. L. (2007). "An empirical study of system improvement by frontline employees in hospital units." Manufacturing Service Oper. Management 9(4): 492-505.

Tyre, M. J. and E. von Hippel (1997). "The situated nature of adaptive learning in organizations." Organ. Sci. 8(1): 71-83.

Uzzi, B. (1997). "Social structure and competition in interfirm networks: The paradox of embeddedness." Admin. Sci. Quart. 42(1): 35-67.

van den Bulte, C. and R. K. Moenaert (1998). "The effects of R\&D team co-location on communication patterns among R\&D, marketing, and manufacturing." Management Sci. 44(11): S1-S18.

von Branconi, C. and C. H. Loch (2004). "Contracting for major projects: Eight business levers for top management." International Journal of Project Management 22(4): 119-130.

Weber, R. A. and C. F. Camerer (2003). "Cultural conflict and merger failure." Management Sci. 49(4): 400-415.

Wegner, D. M. (1987). Transactive memory: A contemporary analysis of the group mind. Theories of Group Behavior. G. Mullen and G. Goethals. New York, Springer-Verlag: 185-208.

Wheelwright, S. C. and K. B. Clark (1992). Revolutionizing Product Development. New York, Free Press.

Wipro. (2008). "About Wipro -> Quality." http://wipro.com/aboutus/quality/quality.htm\#.

Wooldridge, J. M. (2002). Econometric analysis of cross section and panel data. Cambridge, Mass., MIT Press. 